\title{
Porphyromonas gingivalis lipopolysaccharide-induced periodontitis and serum amyloid-beta peptides
}

\author{
Yago Leira ${ }^{\mathrm{a}, \mathrm{b}, *}$, Ramón Iglesias-Rey ${ }^{\mathrm{c}}$, Noemí Gómez-Lado ${ }^{\mathrm{d}}$, Pablo Aguiar ${ }^{\mathrm{d}}$, \\ Francisco Campos $^{\mathrm{c}}$, Francesco D’Aiuto $^{\mathrm{b}}$, José Castillo $^{\mathrm{c}}$, Juan Blanco ${ }^{\mathrm{a}}$, \\ Tomás Sobrino ${ }^{\mathrm{c}, * *}$ \\ ${ }^{\text {a }}$ Periodontology Unit, Faculty of Medicine and Odontology, University of Santiago de Compostela, Medical-Surgical Dentistry \\ (OMEQUI) Research Group, Health Research Institute of Santiago de Compostela (IDIS), Santiago de Compostela, Spain ${ }^{\text {b }}$ \\ Periodontology Unit, UCL Eastman Dental Institute and Hospital, University College London, London, $\mathrm{UK}^{\mathrm{c}} \mathrm{Clinical}^{\mathrm{N}}$ Neurosciences \\ Research Laboratory, Clinical University Hospital, Health Research Institute of Santiago de Compostela (IDIS), Santiago de Compostela, \\ Spain ${ }^{\mathrm{d}}$ Molecular Imaging Group, Clinical University Hospital, Faculty of Medicine, University of Santiago de Compostela, Health \\ Research Institute of Santiago de Compostela (IDIS), Santiago de Compostela, Spain
}

* Corresponding author at: Periodontology Unit - UCL Eastman Dental Institute and Hospital, University College London, 256 Gray’s Inn Road, London WC1X8LD, United Kingdom.

** Corresponding author at: Clinical Neurosciences Research Laboratory, Clinical University Hospital, Travesa da Choupana s/n, Santiago de Compostela, 15706, Spain.

E-mail addresses: y.leira@ucl.ac.uk (Y. Leira), Tomas.Sobrino.Moreiras@sergas.es (T. Sobrino). 


\section{Keywords}

Periodontitis Lipopolysaccharide Porphyromonas gingivalis Amyloid-beta peptides Endothelial dysfunction Cognitive decline 


\section{ABSTRACT}

Objective: The aim of this investigation was to determine the circulating levels of amyloid beta $(\mathrm{A} \beta)$ peptides using the Porphyromonas gingivalis $(\mathrm{Pg})$ lipopolysaccharide (LPS) model to induce periodontitis.

Methods: Experimental periodontitis was induced in 6 male Sprague-Dawley rats.

Alveolar bone loss was measure by micro computed tomography. Serum concentrations of $\mathrm{A} \beta 1-40$ and $\mathrm{A} \beta 1-42$ prior to periodontal induction, at $24 \mathrm{~h}, 7,14$, and 21 days the last injection of Pg-LPS.

Results: The distance between the cemento-enamel junction and the bone crest (i.e., alveolar bone loss) was significantly higher at the end of periodontal induction compared to baseline $(2.92 \pm 0.29 \mathrm{~mm}$ vs. $3.8 \pm 0.28 \mathrm{~mm}, \mathrm{P}<0.001)$. Periodontitis evoked a slight acute elevation of $A \beta 1-40$ serum levels that were maintained during the whole experiment. $A \beta 1-$ 42 peptide levels peak at the end of the study. A positive strong correlation was observed between alveolar bone loss and $\mathrm{A} \beta 1-40$ serum levels at 7 days $(\mathrm{r}=0.695, \mathrm{P}=0.012)$ and as well as with serum $A \beta 1-42$ concentrations at 21 days $(r=0.968, P=0.002)$.

Conclusions: Periodontitis induced Pg-LPS produced increased serum levels of A $\beta$ peptides. Further studies are needed to confirm our results and to investigate the mechanisms by which periodontitis could be associated with an overexpression of $A \beta$. 
Abbreviations: A $\beta$, amyloid beta; AD, Alzheimer's disease; AAP, amyloid precursor protein; $\mathrm{BBB}$, blood-brain barrier; $\mathrm{CEJ}$, cemento-enamel junction; $\mathrm{CV}$, coefficient of variation; LPS, lipopolysaccharide; NF- $\mathrm{B}$, nuclear factor kappa $\mathrm{B} ; \mu \mathrm{CT}$, micro-CT; Pg, Porphyromonas gingivalis; TLR, toll-like receptor 


\section{Introduction}

Amyloid-beta $(\mathrm{A} \beta$ ) is a 38-to 43 amino-acid peptide that is produced by proteolytic cleavage of amyloid precursor protein (APP). Plasma $A \beta$ includes among others $A \beta 1-40$ and $A \beta 1-42$. Whereas early parenchymal $A \beta$ deposition is considered to play a pivotal role in neuronal loss and cognitive impairment in Alzheimer's disease (AD) (Hardy \& Allsop, 1991), progressive $A \beta$ accumulation within the walls of cortical and leptomeningeal small arterioles is the pathological hallmark of cerebral amyloid angiopathy (Charidimou, Gang, $\&$ Werring, 2012). Thus, senile plaque amyloid is primarily comprised of $A \beta 1-42$ and amyloid of vascular origin consists of $A \beta 1-40$ species. AD is one of the leading causes of primary degenerative dementia affecting the elderly (Querfurth \& LaFerla, 2010). The prevalence of $\mathrm{AD}$ is age dependent affecting almost $50 \%$ of individuals aged 85 years or above (Ferri et al., 2005) and it has become a major health issue, especially in developed countries (Ballard et al., 2011). Periodontitis, a chronic infection within the gingiva associated with systemic in- flammation has been related to an increased risk for having AD (Kamer, Dasanayake et al., 2008, Kamer, Craig et al., 2008). Indeed, a recent metaanalysis showed that patients with periodontitis had 1.69-fold increased odds for developing AD compared with those without periodontitis (Leira et al., 2017). It has been postulated that periodontitis could be involved in the synthesis and accumulation of $A \beta$ in the brain. By means of positron emission tomography imaging techniques, periodontitis was associated with $\mathrm{A} \beta$ deposition in brain areas known to be susceptible to $\mathrm{AD}$ (Kamer et al., 2015). Periodontally affected tissues from healthy patients also demonstrated overexpression of APP, therefore, giving insight on the potential relationship between periodontitis and $A \beta$ accumulation (Kubota et al., 2014). Recently, it was found that serum A $\beta 1-42$ levels from patients diagnosed with cognitive impairment who had severe periodontitis were significantly higher than those without cognitive decline or those with lower levels of periodontitis (Gil-Montoya et al., 2017). On the other hand, experimental data suggested that chronic systemic exposure to lipopolysaccharides (LPS) from oral bacteria such as Porphyromonas gingivalis $(\mathrm{Pg})$ could contribute to $\mathrm{A} \beta$ formation and neuroinflammation through cathepsin B (Wu et al., 2017), which is involved in the processing of APP (Hook, Kindy, \& Hook, 2008; Hook, Kindy, Reinheckel, Peters, \& Hook, 2009). 
To the best of our knowledge, there is scarce evidence regarding the potential effect of periodontitis on circulating levels of $A \beta$ peptides. Hence, the goal of this experiment was to evaluate changes of $A \beta 1-40$ and $A \beta 1-42$ serum levels induced by Pg-LPS.

\section{Materials and methods}

\subsection{Experimental design}

Prior to periodontitis induction, micro-CT $(\mu \mathrm{CT})$ examination along with blood extraction (i.e., baseline) was carried out in all animals. In order to induce periodontitis, Pg-LPS injections were performed 3 days per weeks (i.e., Mondays, Wednesdays, and Fridays) during 2 weeks. After the last couple of injections, $\mu \mathrm{CT}$ scan was done to confirm alveolar bone loss. A set of blood extractions was carried out 1 day, 1, 2, and 3 weeks after the last couple of injections. Once all serum samples were stored, determinations of $A \beta$ peptides were done (Fig. 1).

The experimental in vivo investigation was performed in the Clinical Neurosciences Research Laboratory of the University Clinical Hospital of Santiago de Compostela (REGA ES 15078029 2801). The experimental protocol was approved by the Research Commission of the University Clinical Hospital of Santiago de Compostela (ID 15010/ 14/006). All experimental procedures were carried out according to the Animal Care Committee European Union rules and the Spanish regulation (86/609/CEE, 2003/65/CE, 2010/63/EU, RD1201/2005 and RD53/2013). The Animal Research Reporting of In Vivo Experiments guidelines were followed in this study (Kilkenny et al., 2010).

\subsection{Animals and anaesthesia}

Male Sprague-Dawley rats of 7 weeks of age and weighted between 300 and 350g were used in this experiment $(\mathrm{N}=6)$. Animals were housed individually, in stable environmental conditions (environmental temperature of $23{ }^{\circ} \mathrm{C}$ ), relative humidity of $40 \%$ and a light-dark cycle of $12 \mathrm{~h}$, as well as free access to food and water.

Each animal was initially placed into an induction chamber attached to a sevoflurane anaesthetic vaporizer and anaesthesia was induced with $6 \%$ sevoflurane in a $\mathrm{NO}_{2} / \mathrm{O}_{2}$ (70/30) mixture, followed by the application of a nose cone with $4 \%$ sevoflurane in the same pro- portion of the aforementioned gases to maintain anaesthesia during the experimental procedures. During periodontitis induction, all animals were subjected to temperature control, maintaining temperature at $37 \pm 0.5^{\circ} \mathrm{C}$ by a thermostat-controlled 
electric pad (NeoBiotect, Spain).

\subsection{Periodontal induction procedure}

The palatal gingiva between the first and second maxillary molars in both sides (i.e., right and left side) was injected with $10 \mu \mathrm{L}$ of a saline solution containing $1 \mathrm{mg} / \mathrm{mL}$ LPS from Pg (tlrl-pglps, InvivoGen, San Diego, CA) using a Hamilton microsyringe (Agilent, Santa Clara, CA, USA) equipped with a blunted edge 30-gauge needle. This injection was followed by two additional injections at 48-hour intervals as described previously (Kador, O’Meara, Blessing, Marx, \& Reinhardt, 2011). This protocol was repeated the following week (Elburki et al., 2014). Periodontitis induction, hence, lasted 14 days with a total of 6 injections of Pg-LPS per side. In order to have a good access to perform the injections, the animals were placed facing up and the mouth was maintained open with a special microsurgical separator.

All experiments were performed by a single surgeon/periodontist (YL).
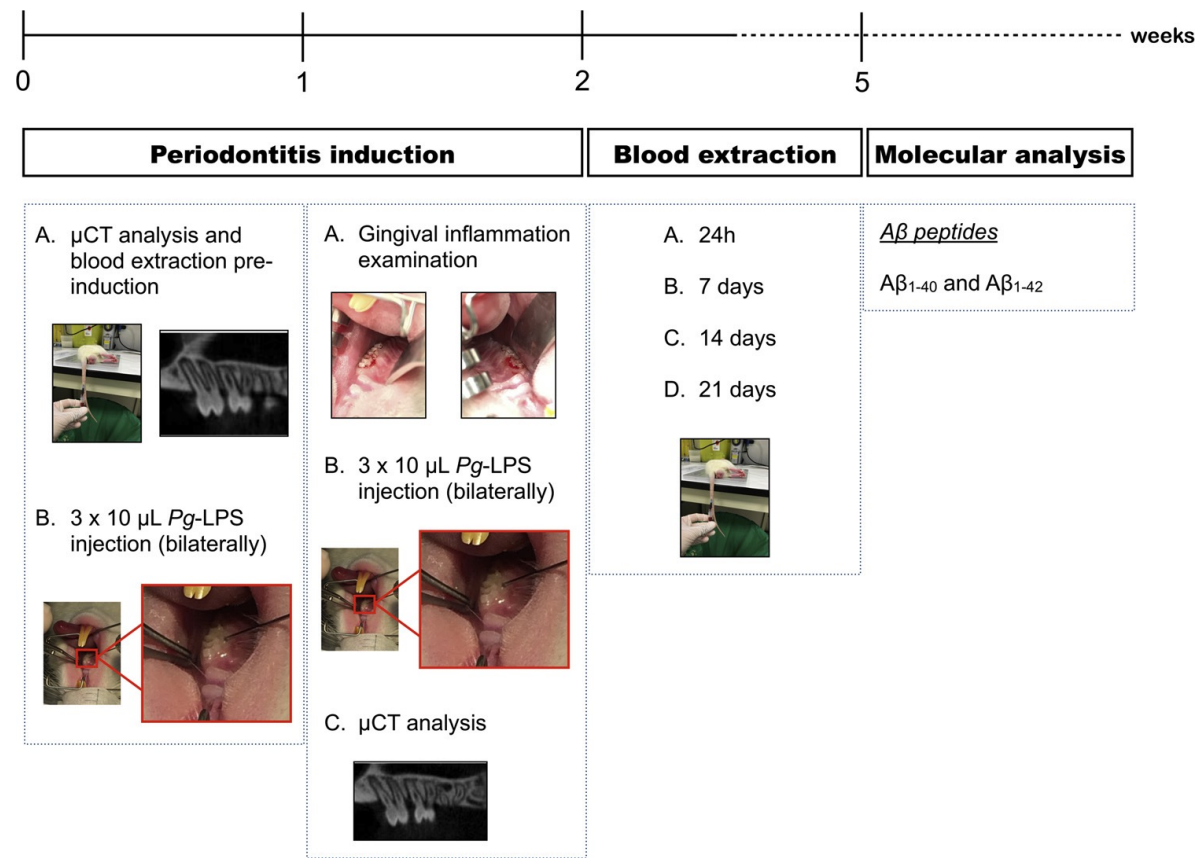

Fig. 1. Experiment outline. 


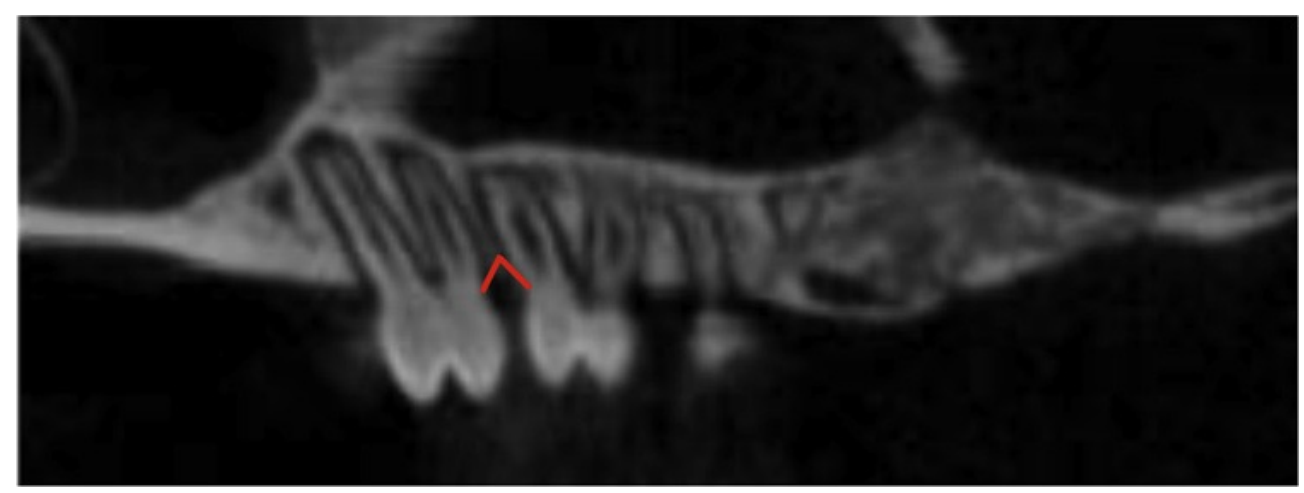

Fig. 2. The distance from the CEJ to the alveolar bone crest was measured at the sagittal plane intersecting the interproximal molars. Red lines depict the measurement that was taken for the distal of $1^{\text {st }}$ molar and mesial of $2^{\text {nd }}$ molar (For interpretation of the references to colour in this figure legend, the reader is referred to the web version of this article).

\subsection{Hard tissues analysis}

To quantify de amount of alveolar bone loss, the bone level was measured bilaterally at the sagittal plane of each animal using a $\mu \mathrm{CT}$ scanner (Bruker BioSpin, Woodbridge, Connecticut, USA) with a voxel size of $0.045 \mathrm{~mm}$ (isotropic voxel) and X-ray energy of 45 $\mathrm{kV}$ and $400 \mu \mathrm{A}$. Crossing the interproximal contact point of the $1^{\text {st }}$ and $2^{\text {nd }}$ molars crown, the distance between de cemento-enamel junction (CEJ) and the alveolar bone crest were measured for the distal surface of the $1^{\text {st }}$ molar and the mesial surface of the $2^{\text {nd }}$ molar just below the contact point and $0.2 \mathrm{~mm}$ palatal to the contact point (Hiyari et al., 2015) at baseline and 14 days (i.e., end of periodontitis induction) (Fig. 2). All $\mu \mathrm{CT}$ analyses were performed by a single biologist (NG-L). 2.5. Serum collection and laboratory tests

\subsection{Laboratory analysis}

Prior to periodontal induction (baseline) and $24 \mathrm{~h}, 7,14$ and 21 days after the last couple of injections, $1800 \mu \mathrm{L}$ of venous blood were collected from the tail of each animal by venepuncture using a 22-gauge needle with a $1 \mathrm{~mL}$ syringe. Blood samples were allowed to clot at room temperature and after $1 \mathrm{~h}$, serum was separated from blood by centrifugation ( 7 min. at $3000 \mathrm{~g}$ ) and $700 \mu \mathrm{L}$ of extracted serum was immediately transferred to $1.5 \mathrm{~mL}$ aliquots. Each aliquot was stored at $-80{ }^{\circ} \mathrm{C}$ until the time of analysis. Serum levels of $A \beta$ peptides were measured by ELISA technique following manufacturer instructions. A $\beta 1-40$ ELISA kit (Fine Test, Wuhan Fine Biotech, Wuhan, China) minimum assay sensitivity was 
$46.875 \mathrm{pg} / \mathrm{ml}$, with an intra-assay coefficient of variation (CV) of 3.2\%; and A $\beta 1-42$ ELISA kit (Fine Test, Wuhan Fine Biotech, Wuhan, China) minimum assay sensitivity was $9.375 \mathrm{pg} / \mathrm{ml}$, with an intra-assay $\mathrm{CV}$ of $2.5 \%$. Determinations were performed in the Clinical Neurosciences Research Laboratory.

\subsection{Statistical analysis}

Mean and standard deviation was calculated for continuous variables, after the method of Shapiro-Wilk was applied to confirm that the data were sampled from a normal distribution. Paired $t$ test and analysis of variance for repeated measures were used to compare differences over time. Additionally, post hoc comparisons were carried out using Bonferroni corrections. Pearson correlation coefficient (r) was used to assess potential correlations between serum $A \beta$ peptides levels and alveolar bone loss. All data analyses were performed with IBM SPSS Statistics 20.0 software for Mac (SPSS Inc., Chicago, IL, USA) and all tests were performed at a significance level of $\alpha=0.05$.

\section{Results}

The distance between CEJ-alveolar bone crest was significantly higher at 14 days in the right side of the maxillae compared to baseline $(1.55 \pm 0.15 \mathrm{~mm}$ vs. $2.02 \pm 0.14 \mathrm{~mm}, \mathrm{P}=$ 0.001). Similarly, this distance was also significantly different in the left side of the upper jaw between baseline and 14 days $(1.37 \pm 0.17 \mathrm{~mm}$ vs. $1.85 \pm 0.15 \mathrm{~mm}, \mathrm{P}<0.001)$. When we combined the measurements of both sides, differences between pre- and postperiodontitis induction in terms of alveolar bone loss were also statistically significant (2.92 $\pm 0.29 \mathrm{~mm}$ vs. $3.8 \pm 0.28 \mathrm{~mm}, \mathrm{P}<0.001)$.

Periodontitis evoked a slight acute elevation of $A \beta 1-40$ serum levels that reached statistical significance compared to baseline and was maintained during the following two weeks. However, at day 21, a reduction in the levels of this biomarker was observed (Fig. 3a). Following experimental periodontitis, $A \beta 1-42$ peptide levels peak much latter than the other $\mathrm{A} \beta$ peptide (i.e., 21 days), confirming its nature of cognitive decline molecule rather than disrupting the vascular endothelial function (Fig. 3b).

While a positive strong correlation was observed between alveolar bone loss and $A \beta 1-40$ serum levels at 7 days (Fig. 4a) and as well as with serum A $\beta 1-42$ concentrations at 21 days (Fig. 4b), no significant correlations were found with the remaining time points for both $\mathrm{A} \beta$ peptides and loss of maxillary bone (data not shown). 
a

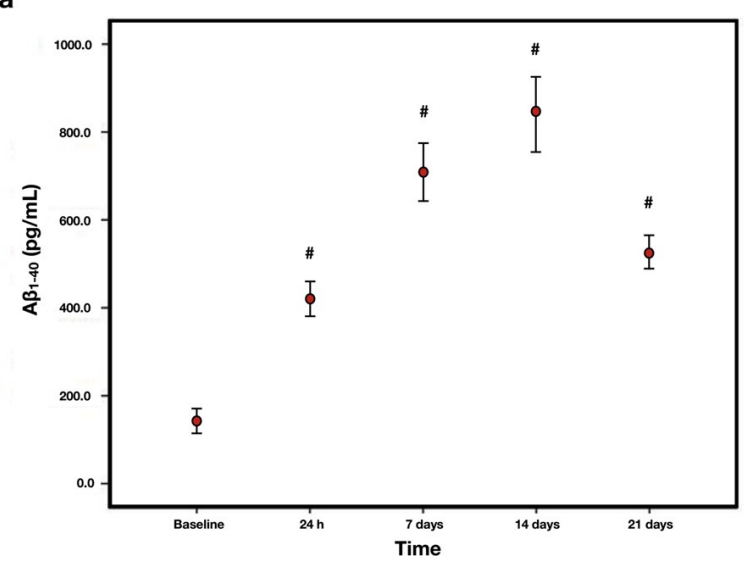

b

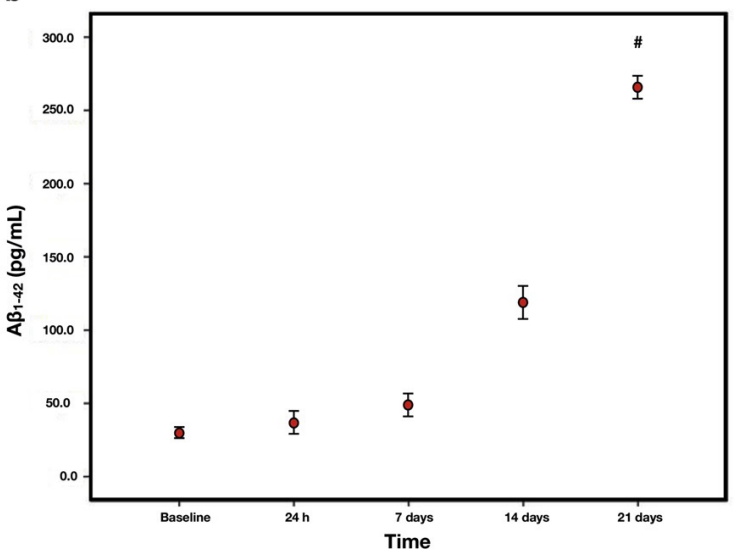

Fig. 3. Changes in serum levels of: a) A $\beta 1-40(\mathrm{pg} / \mathrm{mL})$; b) $\mathrm{A} \beta 1-42(\mathrm{pg} / \mathrm{mL})$ at $24 \mathrm{~h}, 7,14,21$ days after periodontal induction. ${ }^{\#} \mathrm{P}<0.001$ compared to baseline.
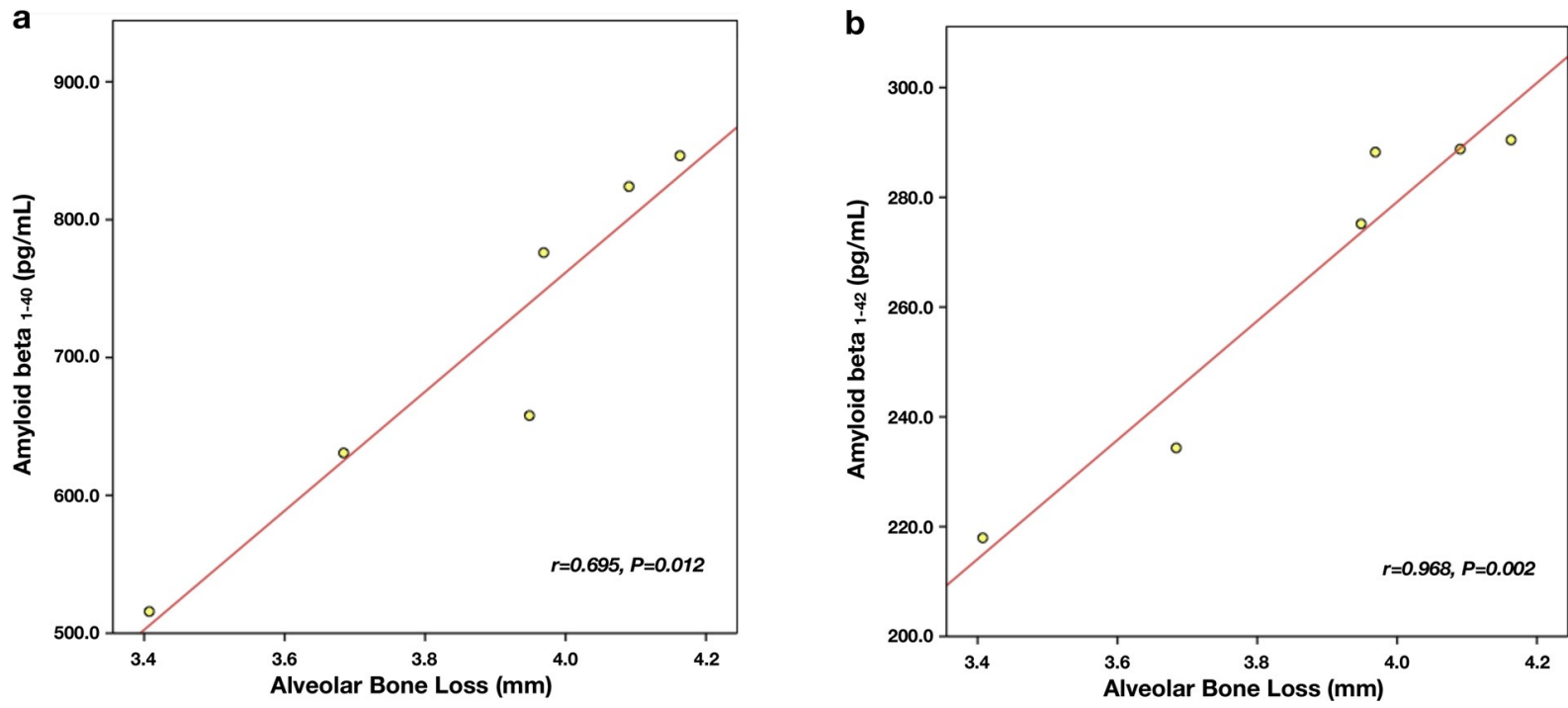

Fig. 4. Correlation between alveolar bone loss and: a) A $\beta 1-40$ levels at 7 days; b) A $\beta 1-42$ levels at 21 days. 


\section{Discussion}

The findings of the present study demonstrated that Pg-LPS induced periodontitis produced an acute increase of circulating levels of $A \beta 1-40$ that were maintained up to day 21 , at the moment in which $A \beta 1-42$ was significantly overexpressed.

Toxic A $\beta$ peptides are involved in brain ischemia. Using the middle cerebral artery occlusion animal model, transgenic mice expressing AAP showed a more pronounced reduction of the cerebral blood flow

than control animals and vasodilation in AAP trangenics was reduced by an $82 \%$, thus, demonstrating that AAP overexpression increased the susceptibility of the brain to ischemic injury (Zhang, Eckman, Younkin, Hsiao, \& Iadecola, 1997). More experimental data demonstrated that circulating $\mathrm{A} \beta 1-40$ is sufficient to induce cerebrovascular dysfunction (Park et al., 2013). A $\beta 1-40$ can cross the blood-brain barrier (BBB) (Zlokovic, 2008) and administration of exogenous $A \beta 1-40$ into the circulation could conceivably enter the brain especially if the BBB is altered (Clifford et al., 2007). In the current experiment, we observed a significant increase in serum levels of $A \beta 1-40$ followed by periodontitis, which is closely related with vascular endothelial dysfunction in the brain. Indeed, circulating levels of $A \beta 1-40$ correlated positively with bone loss at 7 days after periodontal induction, confirming the relationship between periodontal infection and increased systemic levels of this peptide. It has been demonstrated that $A \beta 1-40$ impairs the ability of cerebral endothelial cells to produce vasodilation and such impairment may be mediated by the production of reactive oxygen species (Niwa, Carlson, \& Iadecola, 2000). Accordingly, $\mathrm{A} \beta 1-40$ could be a key mediator in the cerebrovascular alterations resulting from APP over- expression in transgenic mice. In our experiment, however, we did not measure any biomarker of vascular endothelial activation/injury to link periodontitis, A $\beta 1-40$ and endothelial dysfunction.

A pathogenic model has been proposed where LPS from gram-negative bacteria such as Pg binds to toll-like receptors (TLR)-4/CD14 receptors on peripheral monocytes/macrophages, neutrophils and on brain microglia (Zhan, Stamova, \& Sharp, 2018). TLR-4/CD14 activation by LPS leads to nuclear factor (NF)- $\mathrm{kB}$ mediated induction of cytokines in monocytes/neutrophils in blood and from microglia in brain. Since LPS does not enter normal brain when given alone (Banks \& Erickson, 2010; Banks et al., 2015), it is likely 
that other factors con- tribute to LPS entry into ageing brain including cerebral ischemia or hypoxia. Disrupted BBB might aid LPS to enter into the brain. Indeed, LPS from Pg was detected in brains of post-mortem patients diagnosed with AD (Poole, Singhrao, Kesavalu, Curtis, \& Crean, 2013). Once LPS entered brain it would bind TLR-4/CD14 receptors on microglia that would activate NF- $\mathrm{KB}$ mediated increases of intracerebral cytokines. LPS induction of cytokines can increase APP and $\mathrm{A} \beta$ accumulation, which in turn can act on TLR-4 creating a positive feedback loop to increase $A \beta$ (Zhan et al., 2018). In addition, LPS can also acts on the BBB to decrease A $\beta$ exit from brain (Banks et al., 2015). A $\beta 1-42$ accumulation within the neurons is associated with AD-like phenotypes in mice brains. Intracellular $A \beta 1-42$ deposition together with the chronic burden posed by $A \beta$ is toxic to degenerated neurons (Billings, Oddo, Green, McGaugh, \& LaFerla, 2005; Cataldo et al., 2004). In this sense, experimental data showed that systemic chronic systemic exposure to Pg-LPS was associated with learning and memory deficits, intracellular accumulation in neurons and microglia-mediated neuroinflammation within hippocampus (Wu et al., 2017). Our results are supported with clinical data in which it was found that severe periodontal patients had significantly higher $A \beta 1-42$ plasma levels compared to those without periodontitis (Gil-Montoya et al., 2017). In the present experiment, there was a positive correlation between alveolar bone loss and increased levels of $A \beta 1-42$ at 21 days. Periodontally affected tissues of otherwise healthy subjects overexpressed AAP (Kubota et al., 2014) and patients with periodontitis showed high amyloid accumulation compared to those without periodontitis (Kamer et al., 2015). However, it has to be highlighted that accumulation of $\mathrm{A} \beta$ peptides was not measured in the brain of our group of animals. Even though this fact limits our findings, experimental data showed that $A \beta$ is also generated outside the brain. In addition, APP and certain enzymes required for A $\beta$ generation are also overexpressed in peripheral non-neural tissues for example gingiva (Kubota et al., 2014). Hence, $A \beta$ overproduction is widespread in the peripheral organs and tissues in $\mathrm{AD}$ patients, which suggest that peripherally born $\mathrm{A} \beta$ would also contribute to the pathogenesis of AD (Eisele et al., 2014).

Our experiment has several limitations. First of all, our results are based on a modest sample of animals and therefore differences in bone loss and levels of $A \beta$ peptides might simply be occasional. Although the lack of a control group and a sham-operated group 
could be one of the major criticism, we considered the biomarker levels at baseline of each animal as a control per se owing to our main objective was to analyse the influence of periodontitis in each $A \beta$ peptide over time. The animal model that we used in the present study has some shortcomings. The LPS-injections model has a lack of bacterial colonization and the need for constant injections throughout the experiment. However, LPS model is considered to be an direct and easy method for the induction of controlled periodontitis bone loss is localized, the stimulus is constant, and the bone resorption occurs within the first week after the start of the bacterial LPS injections (Dumitrescu, Abd-ElAleem, Morales-Aza, \& Donaldson, 2004). Furthermore, this model of periodontal induction is useful to investigate the host-bacteria interaction and the activation of signalling pathways, pro-inflammatory and vascular dysfunction mediators as well as performance of specific cells or molecules in the pathogenic process of periodontitis (Graves, Fine, Teng, Van Dyke, \& Hajishengallis, 2008). Therefore, we considered this model as the ideal method to carry out our experiment. Lastly, biomarkers of vascular endothelial activation or injury would be of interest to correlate our findings with the function of the endothelium as well as to measure brain accumulation of $A \beta$ peptides.

\section{Conclusions}

Experimental periodontitis is associated with increased levels $A \beta$ of peptides. Studies including larger number of animals should be carried out to confirm our preliminary findings. Further evidence supporting the potential role of periodontitis on endothelial dysfunction and cognitive decline in neurological diseases is also warranted. 


\section{Authorship}

Yago Leira: Conception, design of the work; acquisition, analysis and interpretation of data for the work; drafting the work, revising it critically for important intellectual content; final approval of the version to be published; agreement to be accountable for all aspects of the work in ensuring that questions related to the accuracy or integrity of any part of the work are appropriately investigated and resolved.

Ramón Iglesias-Rey, Noemí Gómez-Lado, Pablo Aguiar, Francisco Campos: Acquisition of data for the work; drafting the work, revising it critically for important intellectual content; final approval of the version to be published; agreement to be accountable for all aspects of the work in ensuring that questions related to the accuracy or integrity of any part of the work are appropriately investigated and resolved.

Francesco D’Aiuto, José Castillo, Juan Blanco, Tomás Sobrino: Conception, design of the work; interpretation of data for the work; revising it critically for important intellectual content; final approval of the version to be published; agreement to be accountable for all aspects of the work in ensuring that questions related to the accuracy or integrity of any part of the work are appropriately investigated and resolved. 


\section{Contributors}

Yago Leira: Study design, periodontal induction, biochemical analysis and manuscript preparation.

Ramón Iglesias-Rey: Periodontal induction and biochemical analysis supervision and manuscript preparation. Noemí Gómez-Lado: Micro-CT analysis and manuscript preparation.

Pablo Aguiar: Micro-CT analysis supervision and manuscript revision.

Francisco Campos: Periodontal induction supervision and manuscript revision.

Francesco D'Aiuto: Study design and manuscript revision.

José Castillo: Study design and funding and manuscript revision.

Juan Blanco: Study design and manuscript revision.

Tomás Sobrino: Biochemical analysis supervision and manuscript revision. 


\section{Funding}

This study was partially supported by grants from the Spanish Ministry of Economy and Competitiveness - Institute of Health Carlos III [grants numbers PI13/02027 and PI15/01578], Spanish Research Network on Cerebrovascular Diseases RETICSINVICTUS [grant number RD12/0014], Xunta de Galicia - Consellería Educación [grant number GRC2014/027] and the European Union program FEDER. The funders had no role in the study design, data collection and analysis, decision to publish, or preparation of the manuscript.

\section{Disclosure of conflict of interest}

The authors have stated explicitly that there are no conflicts of interest in connection with this article. All authors have read and approved the final article.

\section{Acknowledgements}

Y. Leira was supported by a fellowship from the Health Research Institute of Santiago de Compostela (IDIS). Currently, Y. Leira holds a Senior Clinical Research Fellowship supported by the UCL Biomedical Research Centre. Furthermore, F. Campos [CP14/00154] and T. Sobrino [CP12/03121-CPII17/00027] are recipients of a research contract from Miguel Servet Program of Institute of Health Carlos III. 


\section{References}

Ballard, C., Gauthier, S., Corbett, A., Brayne, C., Aarsland, D., \& Jones, E. (2011).

Alzheimer's disease. Lancet, 377, 1019-1031. https://doi.org/10.1016/S01406736(10)61349-9.

Banks, W. A., \& Erickson, M. A. (2010). The blood-brain barrier and immune function and dysfunction. Neurobiology of Disease, 37, 26-32. https://doi.org/10.1016/j.nbd.2009. 07.031 .

Banks, W. A., Gray, A. M., Erickson, M. A., Salameh, T. S., Damodarasamy, M., Sheibani, N., et al. (2015). Lipopolysaccharide-induced blood-brain barrier disruption: Roles of cyclooxygenase, oxidative stress, neuroinflammation, and elements of the neurovascular unit. Journal of Neuroinflammation, 12, 1-15. https://doi.org/10.1186/ s12974-015-0434-1. Billings, L. M., Oddo, S., Green, K. N., McGaugh, J. L., \& LaFerla, F. M. (2005).

Intraneuronal Abeta causes the onset of early Alzheimer's disease-related cognitive deficits in transgenic mice. Neuron, 45, 675-688. https://doi.org/10.1016/j.neuron. 2005.01.040.

Cataldo, A. M., Peterhoff, C. M., Schmidt, S. D., Terio, N. B., Duff, K., Beard, M., et al. (2004). Presenilin mutations in familial Alzheimer disease and transgenic mouse models accelerate neuronal lysosomal pathology. Journal of Neuropathology and Experimental Neurology, 63, 821-830. https://doi.org/10.1093/jnen/63.8.821.

Charidimou, A., Gang, Q., \& Werring, D. J. (2012). Sporadic cerebral amyloid angiopathy revisited: Recent insights into pathophysiology and clinical spectrum. Journal of Neurology, Neurosurgery, and Psychiatry, 83, 124-137. https://doi.org/10.1136/jnnp2011-301308.

Clifford, P. M., Zarrabi, S., Siu, G., Kinsler, K. J., Kosciuk, M. C., Venkataraman, V., et al. (2007). Abeta peptides can enter the brain through a defective blood-brain barrier and bind selectively to neurons. Brain Research, 1142, 223-226. https://doi.org/10.

1016/j.brainres.2007.01.070.

Dumitrescu, A. L., Abd-El-Aleem, S., Morales-Aza, B., \& Donaldson, L. F. (2004). A model of periodontitis in rat: Effect of lipopolysaccharide on bone resorption, osteoclast activity, and local peptidergic innervation. Journal of Clinical Periodontology, 31, 596-603. https://doi.org/10.1111/j.1600-051X.2004.00528.x.

Eisele, Y. S., Fritschi, S. K., Hamaguchi, T., Obermüller, U., Füger, P., Skodras, A., et al. 
(2014). Multiple factors contribute to the peripheral induction of cerebral $\beta$-amyloidosis. Journal of Neuroscience, 34, 10264-10273. https://doi.org/10.1523/ JNEUROSCI.160814.2014 .

Elburki, M. S., Rossa, C., Guimaraes, M. R., Goodenough, M., Lee, H. M., Curylofo, F. A., et al. (2014). A novel chemically modified curcumin reduces severity of experimental periodontal disease in rats: Initial observations. Mediators of Inflammation, 2014, 1-10. https://doi.org/10.1155/2014/959471.

Ferri, C. P., Prince, M., Brayne, C., Brodaty, H., Fratigglioni, L., Ganguli, M., et al. (2005). Alzheimer's disease International. Global prevalence of dementia: A Delphi consensus study. Lancet, 366, 2112-2127. https://doi.org/10.1016/S0140-6736(05)67889-0. Gil-Montoya, J. A., Barrios, R., Santana, S., Sanchez-Lara, I., Pardo, C. C., FornielesRubio, F., et al. (2017). Association between periodontitis and amyloid $\beta$ peptide in elderly people with and without cognitive impairment. Journal of Periodontology, 88, 1051-1058. https://doi.org/10.1902/jop.2017.170071.

Graves, D. T., Fine, D., Teng, Y. T., Van Dyke, T. E., \& Hajishengallis, G. (2008). The use of rodent models to investigate host-bacteria interactions related to periodontal dis- eases. Journal of Clinical Periodontology, 35, 89-105. https://doi.org/10.1111/j.1600051X.2007.01172.x.

Hardy, J., \& Allsop, D. (1991). Amyloid deposition as the central event in the aetiology of Alzheimer's disease. Trends in Pharmacological Sciences, 12, 383-388. https://doi.org/ 10.1016/0165-6147(91)90609-V.

Hiyari, S., Atti, E., Camargo, P. M., Eskin, E., Lusis, A. J., Tetradis, S., et al. (2015). Heritability of periodontal bone loss in mice. Journal of Periodontal Research, 50, 730-736. https://doi.org/10.1111/jre.12258.

Hook, V. Y., Kindy, M., \& Hook, G. (2008). Inhibitors of cathepsin B improve memory and reduce beta-amyloid in transgenic Alzheimer disease mice expressing the wild- type, but not the Swedish mutant, beta-secretase site of the amyloid precursor protein. The Journal of Biological Chemistry, 283, 7745-7753. https://doi.org/10.1074/jbc. M708362200.

Hook, V. Y., Kindy, M., Reinheckel, T., Peters, C., \& Hook, G. (2009). Genetic cathepsin $\mathrm{B}$ deficiency reduces beta-amyloid in transgenic mice expressing human wild- type 
amyloid precursor protein. Biochemical and Biophysical Research Communications, 386, 284-288. https://doi.org/10.1016/j.bbrc.2009.05.131.

Kador, P. F., O’Meara, J. D., Blessing, K., Marx, D. B., \& Reinhardt, R. A. (2011).

Efficacy of structurally diverse aldose reductase inhibitors on experimental periodontitis in rats. Journal of Periodontology, 82, 926-933. https://doi.org/10.1902/jop.2010.

Kamer, A. R., Pirraglia, E., Tsui, W., Rusinek, H., Vallabhajosula, S., Mosconi, L., et al. (2015). Periodontal disease associates with higher brain amyloid load in normal elderly. Neurobiology of Aging, 36, 627-633. https://doi.org/10.1016/j.neurobiolaging. 2014.10.038.

Kamer, A. R., Craig, R. G., Dasanayake, A. P., Brys, M., Glodzik-Sobanska, L., \& de Leon, M. J. (2008). Inflammation and Alzheimer's disease: Possible role of periodontal diseases. Alzheimers \& Dementia, 4, 242-250. https://doi.org/10.1016/j.jalz.2007.08. 004. Kamer, A. R., Dasanayake, A. P., Craig, R. G., Glodzik-Sobanska, L., Bry, M., \& de Leon, M. J. (2008). Alzheimer's disease and peripheral infections: The possible contribution from periodontal infections, model and hypothesis. Journal of Alzheimers Disease, 13, 437-449. https://doi.org/10.3233/JAD-2008-13408.

Kilkenny, C., Browne, W., Cuthill, I. C., Emerson, M., Altman, D. G., \& NC3Rs Reporting Guidelines Working Group (2010). Animal research: Reporting in vivo experiments: The ARRIVE guidelines. British Journal of Pharmacology, 160, 1577-1579. https://doi. $\operatorname{org} / 10.1111 /$ j.1476-5381.2010.00872.x.

Kubota, T., Maruyama, S., Abe, D., Tomita, T., Morozumi, T., Nakasone, N., et al. (2014). Amyloid beta (A4) precursor protein expression in human periodontitis-affected gingival tissues. Archives of Oral Biology, 59, 586-594. https://doi.org/10.1016/j. archoralbio.2014.03.004.

Leira, Y., Domínguez, C., Seoane, J., Seoane-Romero, J., Pías-Peleteiro, J. M., Takkouche, B., et al. (2017). Is periodontal disease associated with Alzheimer ś disease? A sys- tematic review and meta-analysis. Neuroepidemiology, 48, 21-31. https://doi.org/10. $1159 / 000458411$.

Niwa, K., Carlson, G. A., \& Iadecola, C. (2000). Exogenous A beta1-40 reproduces cerebrovascular alterations resulting form amyloid precursor protein overexpression in mice. Journal of Cerebral Blood Flow \& Metabolism, 20, 1659-1668. https://doi.org/ 
10.1097/00004647-200012000-00005.

Park, L., Zhou, P., Koizumi, K., El Jamal, S., Previti, M. L., Van Nostrand, W. E., et al. (2013). Brain and circulating levels of A $\beta 1-40$ differentially contribute to vasomotor dysfunction in the mouse brain. Stroke, 44, 198-204. https://doi.org/10.1161/ STROKEAHA.112.670976.

Poole, S., Singhrao, S. K., Kesavalu, L., Curtis, M. A., \& Crean, S. (2013). Determining the presence of periodontopathic virulence factors in short-term postmortem Alzheimer's disease brain tissue. Journal of Alzheimers Disease, 36, 665-677. https://doi.org/10. 3233/JAD-121918.

Querfurth, H. W., \& LaFerla, F. M. (2010). Alzheimer's disease. The New England Journal of Medicine, 362, 329-344. https://doi.org/10.1056/NEJMra0909142.

Wu, Z., Ni, J., Liu, Y., Teeling, J. L., Takayama, F., Collcutt, A., et al. (2017). Cathepsin B plays a critical role in inducing Alzheimer's disease-like phenotypes following chronic systemic exposure to lipopolysaccharide from Porphyromonas gingivalis in mice. Brain, Behaviour, and Immunity, 65, 350-361. https://doi.org/10.1016/j.bbi. 2017.06.002.

Zhan, X., Stamova, B., \& Sharp, F. R. (2018). Lipopolysaccharide associates with amyloid plaques, neurons and oligoendrocytes in Alzheimer ś disease brain: A review. Frontiers in Aging Neuroscience, 10, 1-14. https://doi.org/10.3389/fnagi.2018.00042.

Zhang, F., Eckman, C., Younkin, S., Hsiao, K. K., \& Iadecola, C. (1997). Increased susceptibility to ischemic brain damage in transgenic mice overexpressing the amyloid precursor protein. Journal of Neuroscience, 17, 7655-7661. https://doi.org/10.1523/ JNEUROSCI.17-20-07655.1997.

Zlokovic, B. V. (2008). The blood-brain barrier in health and chronic neurodegenerative disorders. Neuron, 57, 178-201. https://doi.org/10.1016/j.neuron.2008.01.003. 